\title{
Defect annealing and thermal desorption of deuterium in low dose HFIR neutron-irradiated tungsten
}

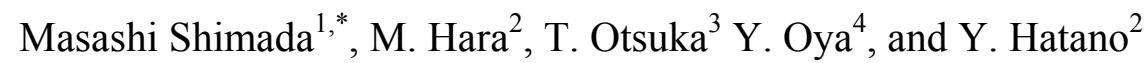 \\ ${ }^{1}$ Fusion Safety Program, Idaho National Laboratory, Idaho Falls, ID, U.S.A. \\ ${ }^{2}$ Hydrogen Isotope Research Center, University of Toyama, Toyama, Japan \\ ${ }^{3}$ Kyushu University, Interdisciplinary Graduate School of Engineering Science, Higashi-ku, Fukuoka, Japan \\ ${ }^{4}$ Radioscience Research Laboratory, Faculty of Science, Shizuoka University, Shizuoka, Japan
}

\section{$\underline{\text { Abstract }}-$}

Three tungsten samples irradiated at High Flux Isotope Reactor at Oak Ridge National Laboratory were exposed to deuterium plasma (ion fluence of $1 \times 10^{26} \mathrm{~m}^{-2}$ ) at three different temperatures ( 100 , 200, and $500^{\circ} \mathrm{C}$ ) in Tritium Plasma Experiment at Idaho National Laboratory. Subsequently, thermal desorption spectroscopy was performed with a ramp rate of $10{ }^{\circ} \mathrm{C} \mathrm{min}^{-1}$ up to $900{ }^{\circ} \mathrm{C}$, and the samples were annealed at $900{ }^{\circ} \mathrm{C}$ for 0.5 hour. These procedures were repeated three times to uncover defectannealing effects on deuterium retention. The results show that d euterium retention decreases approximately $70 \%$ for at $500{ }^{\circ} \mathrm{C}$ after each annealing, and radiation damages were not annealed out completely even after the $3^{\text {rd }}$ annealing. TMAP modeling revealed the trap concentration decreases approximately $80 \%$ after each annealing at $900{ }^{\circ} \mathrm{C}$ for 0.5 hour.

PSI-21 keywords: Tungsten, Neutron damage, Desorption, Deuterium inventory

PACS codes: $52.40 . \mathrm{Hf}, 52.77 . \mathrm{Dq}, 61.80 .-\mathrm{x}, 68.43 . \mathrm{Vx}$

*Corresponding author address: P.O. Box 1625, MS 7113, Idaho Falls, ID, 83415-7113, U.S.A.

*Corresponding author's e-mail: Masashi.Shimada@inl.gov

Presenting author: Masashi Shimada

Presenting author's e-mail: Masashi.Shimada@inl.gov 


\section{Introduction}

Accurately estimating tritium retention in plasma facing components (PFCs) and minimizing its uncertainty a re $\mathrm{k}$ ey saf ety i ssues $\mathrm{f}$ or $\mathrm{l}$ icensing DEMO an $\mathrm{d}$ future $\mathrm{f}$ usion $\mathrm{p}$ ower $\mathrm{r}$ eactors [1-3]. Deuterium-tritium fusion reactions produce $14 \mathrm{MeV}$ neutrons that activate PFCs and create radiation defects throughout the bulk of the material of these components. Recent studies showed that tritium was trapped in bulk ( $>10 \mu \mathrm{m})$ tungsten beyond the detection range of nuclear r eaction an alysis technique [4-5], and thermal desorption spectroscopy (TDS) technique becomes the only established diagnostic that can reveal hydrogen isotope behavior in bulk $(>>10 \mu \mathrm{m})$ tungsten. Radiation damage and its recovery mechanisms in neutron-irradiated tungsten are still poorly understood, and neutronirradiation data of tungsten is very limited [6]. In this paper, sy stematic investigation with repeated plasma exposures, thermal desorption and annealing is performed to study defect-annealing effect on thermal desorption of deuterium in low dose neutron-irradiated tungsten.

\section{Experimental Apparatus}

The disc-type tungsten samples $(\phi 6.0 \mathrm{~mm} \times 0.2 \mathrm{~mm})$ were prepared by cutting polycrystalline tungsten rod (99.99 a t. \% pur ity, from A.L.M.T. C o., J apan) a nnealed at $900^{\circ} \mathrm{C}$ for 1 hour in a hydrogen atmosphere to relieve internal stresses in the manufacturing process. Details of the sample preparation and ne utron i rradiation a re described el sewhere [5]. Three $t$ ungsten sa mples wer e irradiated by neutrons in the High F lux I sotope Reactor (HFIR), Oak Ridge National Laboratory at reactor co olant temperature $\left(50-70^{\circ} \mathrm{C}\right)$ to low displacement da mage of 0.025 displacement per at om (dpa) under the framework of the US-Japan TITAN program (2007-2013). The thermal neutron and fast ne utron $(>0.1 \mathrm{MeV})$ f luxes a $\mathrm{t} t$ he i rradiation 1 ocation were $2.5 \times 10^{19}$, a nd $8.9 \times 10^{18} \mathrm{~m}^{-2} \mathrm{~s}^{-1}$, respectively. The thermal neutron and fast neutron $(>0.1 \mathrm{MeV})$ fluences for 33 hour irradiation were $3.0 \times 10^{24}$ and $1.1 \times 10^{24} \mathrm{~m}^{-2}$, r espectively. Th is fast neutron $(>0.1 \mathrm{MeV})$ fluence gives damage 1 evel approximately $0.025 \mathrm{dpa}$. Three $0.025 \mathrm{dpa}$ tungsten samples were exposed to deuterium plasma (ion fluence of $\left.1 \times 10^{26} \mathrm{~m}^{-2}\right)$ at three different temperatures $\left(100,200\right.$, and $\left.500{ }^{\circ} \mathrm{C}\right)$ in Tritium Plasma Experiment (TPE) at Idaho National Laboratory. Three non-irradiated ( $0 \mathrm{dpa})$ tungsten samples also were ex posed to deuterium plasma at three different temperatures, an d the TPE ex posure and TDS 
procedures were repeated (once for $100{ }^{\circ} \mathrm{C}$, three times for $200{ }^{\circ} \mathrm{C}$ sample, and twice for $500{ }^{\circ} \mathrm{C}$ ) to compare defect-annealing effects on deuterium retention in non-irradiated ( $0 \mathrm{dpa})$ tungsten. Details of the TPE linear plasma device and thermal desorption system are described elsewhere [7]. Since disctype s amples $\mathrm{w}$ ere pr epared b y c utting polycrystalline $\mathrm{t}$ ungsten rod, a va riation i $\mathrm{n} t$ he $\mathrm{s}$ ample thickness made i $\mathrm{t}$ challenging t $\mathrm{o}$ o btain i dentical flux a nd $\mathrm{t}$ emperature $\mathrm{c}$ onditions $\mathrm{f}$ or different thickness sample. Deuterium ion flux was varied from $0.5 \times 10^{22}$ to $1.2 \times 10^{22} \mathrm{~m}^{-2} \mathrm{~s}^{-1}$ to keep identical exposure temperature. The recent report indicated that there exists strong dependence of ion fluence on tritium retention and less de pendence of $i$ on flux [8]. T herefore, the i on fluences in each TPE plasma exposure w ere ke pt a pproximately $1 \times 10^{26} \mathrm{~m}^{-2}$ as shown in table 1 . Subsequently, thermal desorption spectroscopy (TDS) was performed with a ramp rate of $10{ }^{\circ} \mathrm{C} / \mathrm{min}$ up to $900{ }^{\circ} \mathrm{C}$, and then the samples were an nealed at $900^{\circ} \mathrm{C}$ for 0.5 hour at the end of the TDS. These procedures were repeated to unc over defect-annealing mechanisms and i ts ef fects o $\mathrm{n} d$ euterium retention. $\mathrm{T}$ hese samples were used for previous nuclear reaction analysis (NRA) study $[4-5,9]$ and the time interval between plasma exposure at TPE and TDS were approximately 600 days for the non-anneal sample due to r adioactive material ha ndling a nd s hipping to/from NRA facility. For the $1^{\text {st }}, 2^{\text {nd }}$, a nd $3^{\text {rd }}$ annealed sample, the time interval between plasma exposure at TPE and TDS were kept identical at 19 hours. Therefore, near surface deuterium in the non-annealed sample (especially 100 and $200{ }^{\circ} \mathrm{C}$ ) might have desorbed during this 600 days time in terval due to isotope exchange with hydrogen. In this study we denote the samples performed no TDS and no annealing after neutron-irradiation prior to TPE exposure as "no-anneal", the samples performed one TDS and one annealing prior to TPE exposure as "af ter $1^{\text {st }}$ anneal", the samples p erformed two TDS an d two annealing prior to TPE exposure as "after $2^{\text {nd }}$ anneal", and the samples performed three TDS and three annealing prior to TPE exposure as " after $3^{\text {rd }}$ anneal". Positron a nnihilation s pectroscopy c onfirmed t he e xposure temperatures of $<500^{\circ} \mathrm{Ch}$ ave 1 ittle ef fects i $\mathrm{n}$ defect recovery compared $\mathrm{w}$ ith the annealing temperature of $900{ }^{\circ} \mathrm{C}[10]$.

\section{Numerical Analysis}

TMAP (Tritium Migration Analysis Program) was developed by fusion safety program, INL in 1980 's to dynamically an alyze $d$ issolved $g$ as movement $t$ hrough st ructure, $b$ etween st ructures an d 
adjoining enclosures, and among enclosures for safety an alysis purpose. TMAP has application to a much w ider variety of pr oblems, a nd has be en w idely us ed in the P FC c ommunity t o simulate hydrogen isotope behavior in the PFCs [11-12]. A recent extension of the TMAP trap-site model was successfully carried out in the version 4 (TMAP4) to include as many traps as required by the user to simulate $\mathrm{r}$ etention of $\mathrm{t}$ ritium i $\mathrm{n}$ ne utron da maged $\mathrm{t}$ ungsten $\mathrm{m}$ aterial [13]. Details o $\mathrm{f} t$ he T MAP simulation and mass transport property used in tungsten are described elsewhere $[9,13]$. In this study the e nhanced di ffusion $\mathrm{z}$ one ( EDZ) $\mathrm{m}$ odel $\mathrm{t}$ hat Venhaus a nd $\mathrm{C}$ ausey $\mathrm{s}$ imulated $\mathrm{t}$ ritium $\mathrm{pl}$ asma implantation was used to simulate both plasma exposure phase and thermal desorption phase in order to accu rately el ucidate deuterium be havior i n ne utron-irradiated tungsten [14-17]. Experimental sample transfer procedure in air from the TPE vacuum chamber to the TDS vacuum chamber was not simulated, and the sample were assumed to be in vacuum at room temperature for 19 hours from the end of pl asma e xposure t o the be ginning of T DS instead. Venhaus an $\mathrm{d} C$ ausey ad justed $\mathrm{t}$ he diffusivity in the EDZ from $5.0 \times 10^{-10}$ to $2.0 \times 10^{-9} \mathrm{~m}^{2} / \mathrm{s}$ to fit e xperimental $\mathrm{d}$ ata. I $\mathrm{n}$ th is paper we utilized the EDZ in ion implantation zone $(<10 \mathrm{~nm})$, and varies the deuterium diffusivity in the similar range from $0.9 \times 10^{-10}$ to $5.0 \times 10^{-10} \mathrm{~m}^{2} / \mathrm{s}$ to fit experimental data. Deuterium implantation profile (100 $\mathrm{eV} \mathrm{D}^{+}$in $\mathrm{W}$ ) obtained from the SRIM code with the displacement energy of $90 \mathrm{eV}$ was used for this simulation [18]. Hydrogen diffusivity formula (corrected for deuterium) by Frauenfelder was used in normal diffusion zone (NDZ), which is beyond $10 \mathrm{~nm}$ from surface [19]. Recombination coefficients vary by several or ders of magnitude in the literature, and the recombination c oefficient formula by Anderl at al $[20]\left(\mathrm{K}_{\mathrm{r}}=3.2 \times 10^{-15} \exp (-1.16 \mathrm{eV} / \mathrm{kT})\left[\mathrm{m}^{4} / \mathrm{s}\right]\right)$ wa s used. $\mathrm{T}$ his recombination coefficient is high enough to treat surface deuterium concentration to zero; therefore, we treat the surface deuterium concentration to be zero as a boundary condition in this simulation as suggested by Causey et.al. [1416]. Uniform distribution of empty traps with user specified concentration is introduced first, and the deuterium $\mathrm{pl}$ asma e xposure is simulated wi th si milar $\mathrm{d}$ euterium $\mathrm{i}$ on flux a nd $\mathrm{t}$ emperature profile obtained ex perimentally to investigate d euterium behavior (e.g. how deep deuterium at oms migrate and $t$ rap) in tungsten. $T$ hen, the thermal de sorption phase wer e si mulated wi th $t$ he $r$ amp-rate of $0.167{ }^{\circ} \mathrm{C} \mathrm{s}^{-1}\left(=10^{\circ} \mathrm{C} \mathrm{min}^{-1}\right)$ and the maximum temperature of $900{ }^{\circ} \mathrm{C}$. There are three types of fitting parameters in this modeling. The diffusivity in the EDZ determines deuterium solution concentration 
penetrating into the NDZ; therefore it governs how deep deuterium atom can migrate with given trap concentration and detrapping e nergy. Effective diffusivity decreases a s the trap co ncentration and detrapping energy increase. In general, the first fitting parameter, detrapping energy, can be determined by the TDS peak positions, and the second fitting parameter, trap concentration, $\mathrm{c}$ an be obtained by the maximum de uterium flux (peak height) of TDS peak. Two detrapping energies of $1.25( \pm 0.15) \mathrm{eV}$ and $1.70( \pm 0.10) \mathrm{eV}$ were used in this study. Uniform trap concentration throughout sample $\mathrm{t}$ hickness was $\mathrm{u}$ sed $\mathrm{f}$ or si mplicity an d due t o u navailability of de uterium de pth profile diagnostic in bulk W $(>5 \mu \mathrm{m})$. The third fitting parameter, diffusivity in the EDZ, can be acquired from the shape (width) of TDS peak.

\section{Results and Discussion}

According to the review of defect recovery in tungsten [6], the stage III recovery, which is attributed to the migration of mono-vacancies, wa s observed around $300-400{ }^{\circ} \mathrm{C}$, and the migration energy of mono-vacancy were reported to be approximately $1.7 \mathrm{eV}$. F or the sample exposed at 100 and $200{ }^{\circ} \mathrm{C}$, the sa mple t emperature was k ept b elow the st age III r ecovery temperature to prevent defect recovery during the de uterium plasma exposure, and the effect of diffusion on the deuterium depth profile is evaluated. In fact the TDS spectra of $100{ }^{\circ} \mathrm{C}$ exposure are very similar to that of $200^{\circ} \mathrm{C}$ exposure. Almost all the deuterium atoms were desorbed or isotope-exchanged hydrogen in the non-annealed $100^{\circ} \mathrm{C}$ exposed sample during the long time interval ( $\sim 600$ days) between plasma exposure and T DS for the non-anneal sa mple, and it showed ne gligibly s mall deuterium retention, making it difficult to compare with annealed results. For the sample exposed at $500{ }^{\circ} \mathrm{C}$, the sample temperature was above the stage III recovery temperature, and the effects of the stage III recovery on deuterium retention is ev aluated. The stage $\mathrm{V}$ r ecovery is reported to oc cur slightly be low $900{ }^{\circ} \mathrm{C}$, which is a ttributed t o m igration of vacancy cl usters, $\mathrm{b}$ ut $\mathrm{t}$ he size o f $\mathrm{v}$ acancy $\mathrm{cl}$ usters wer e $\mathrm{n}$ ot identified in the literature [6]. Therefore; the annealing at $900{ }^{\circ} \mathrm{C}$ for 0.5 hour was chosen as annealing temperature and dur ation $\mathrm{t} o$ reveal $\mathrm{t}$ he $\mathrm{d}$ efect-annealing ef fects of $\mathrm{v}$ acancy $\mathrm{cl}$ usters on $\mathrm{t}$ hermal desorption spectra and deuterium retention. 
Figure 1 sh ows the thermal d esorption spectra of an nealed n eutron-irradiated tungsten samples exposed to the ion fluence of $1 \times 10^{26} \mathrm{~m}^{-2}$ at (a) $200^{\circ} \mathrm{C}$ and (b) $500{ }^{\circ} \mathrm{C}$. For $200^{\circ} \mathrm{C}$ case, Figure $1 \mathrm{a}$ shows similar profiles with two distinctive peaks: a low temperature peak located around $250-350{ }^{\circ} \mathrm{C}$, and a high temperature peak located around $500-600{ }^{\circ} \mathrm{C}$. The maximum de uterium de sorption flux increased from "no-anneal" to "after $1^{\text {st }}$ anneal". It is important to note that only the low temperature peak located around $250-350^{\circ} \mathrm{C}$ w as obs erved from the non-irradiated ( 0 dpa) $200^{\circ} \mathrm{C}$ s ample (not shown) and there was no distinctive change in deuterium retention due to annealing. For $500{ }^{\circ} \mathrm{C}$ case, Figure $1 \mathrm{~b}$ shows similar profiles with one distinctive peak located different temperature around 750$850{ }^{\circ} \mathrm{C}$ for "no-anneal" and $500-600^{\circ} \mathrm{C}$ for the sample after $1^{\text {st }}, 2^{\text {nd }}$, and $3^{\text {rd }}$ anneal. Negligible small deuterium retention below $9.0 \times 10^{16} \mathrm{~m}^{-2}$ was observed from the non-irradiated ( $\left.0 \mathrm{dpa}\right) 500{ }^{\circ} \mathrm{C}$ sample (not s hown) and there w as no distinctive c hange in de uterium $r$ etention $d$ ue to a nnealing. It is interesting to note that figure $1 \mathrm{~b}\left(500{ }^{\circ} \mathrm{C}\right.$ case $)$ showed consistent trend in thermal desorption behavior after $1^{\text {st }}, 2^{\text {nd }}$, and $3^{\text {rd }}$ anneal, but figure $1 \mathrm{a}\left(200^{\circ} \mathrm{C}\right.$ case $)$ did not show any trend after $1^{\text {st }}, 2^{\text {nd }}$, and $3^{\text {rd }}$ anneal. Near surface retention $(<\mathrm{a}$ few $\mu \mathrm{m})$ is the major contributor to deuterium retention in $200^{\circ} \mathrm{C}$ results, wh ereas b ulk r etention ( $>10 \mu \mathrm{m})$ predominates deuterium $\mathrm{r}$ etention in $500^{\circ} \mathrm{C} \mathrm{r}$ esults. Deuterium irradiation effect (from high-flux plasma) can not be distinguished with neutron (or highenergy ion) irradiated damage at near surface $(<\mathrm{a}$ few $\mu \mathrm{m})$ since high s olution $\mathrm{c}$ oncentration of deuterium atoms in tungsten lattice creates additional ion-induced damage and trap site such as bubble or bl ister formations, making it c hallenging to u nderstand de fect recovery at ne ar s urface (for the $200{ }^{\circ} \mathrm{C}$ case) when trapped deuterium atoms are used as a defect detector. The different behavior can be attributed to bubble or blister formations at near surface. F urther investigation with transmission electron microscopy and positron an nihilation spectroscopy is necessary to reveal different behavior in d efect r ecovery b etween $200^{\circ} \mathrm{C}$ an $\mathrm{d} 500^{\circ} \mathrm{C}$. Figure 2 sh ows defect-annealing ef fects on (a) deuterium retention obtained experimentally via TDS and (b) trap concentration obtained numerically via TMAP at tw o different plasma exposure temperatures $\left(200\right.$ and $\left.500^{\circ} \mathrm{C}\right)$. D euterium retention was obt ained b y i ntegrating deuterium de sorption $\mathrm{flux}$ i $\mathrm{n}$ the $\mathrm{T}$ DS sp ectrum in F igure 1. Trap concentration was obtained by fitting experimental TDS spectrum with detrapping energy in TMAP. Detrapping energy was also obtained by TMAP, and it is interesting to note that the detrapping energy 
of $500{ }^{\circ} \mathrm{C}$ changes from 1.75 to $1.6 \mathrm{eV}$ at the $1^{\text {st }}$ annealing. This could be defect structure change due to $m$ igration of va cancy c luster t o f orm 1 arger va cancy c luster or voi ds. Note that near su rface deuterium retention of non-annealed $200{ }^{\circ} \mathrm{C}$ sa mple was underestimated since thermal desorption of non-annealed samples were performed in approximately 600 da y after plasma exposure. However, this long time interval has minimal effects on bulk deuterium retention of non-annealed $500{ }^{\circ} \mathrm{C}$ sample; therefore, it sh ows consistent defect-annealing trends. Figure 2a shows that the de uterium retention decreases ap proximately $70 \%$ for at $500{ }^{\circ} \mathrm{C}$ after each annealing, all the radiation damage was not annealed out completely even after the $3^{\text {rd }}$ annealing. Deuterium retention is a function of various factors (e.g. plasma ion flux, exposure temperature, plasma duration, trap concentration, and detrapping energy), and trap concentration is more suited for investigating defect-annealing effects. In the $\mathrm{s}$ implified pi cture, de uterium $\mathrm{r}$ etention is product of de uterium $\mathrm{c}$ oncentration a nd de uterium penetration depth, and deuterium diffusion determines this deuterium penetration depth. Presence of trap site has significant effect on de uterium diffusion [4, 21]. According to Oriani [21], the effective diffusivity $D_{\text {eff }}$ under trapping effects can be written as $D_{\text {eff }}=D_{L} /\left(1+\exp \left(E_{\text {bin }} / k T\right) C_{t} / C_{L}\right)$, where $D_{L}$ is the diffusion c oefficient of $\mathrm{H}$ in a normal la ttice of $\mathrm{W}, \mathrm{C}_{\mathrm{t}}$ is the $\mathrm{trap}$ concentration, $\mathrm{C}_{\mathrm{L}}$ is the concentration of in terstitial $\mathrm{s}$ ites, a nd $\mathrm{E}_{\mathrm{bin}}$ is $\mathrm{t}$ he binding e nergy. Figure $2 \mathrm{~b}$ shows that the $\mathrm{t}$ rap concentration obtained from T MAP modeling decreases ap proximately $80 \%$ for $900^{\circ} \mathrm{C}$ e xposure sample after each a nnealing at $900^{\circ} \mathrm{C}$ for 0.5 ho ur, in dicating that deuterium atom wa s migrated slightly $d$ eeper af ter eac $\mathrm{h}$ an nealing due $\mathrm{t}$ o sl ight $\mathrm{i}$ ncrease $\mathrm{i} \mathrm{n}$ ef fective $\mathrm{d}$ iffusivity as the $\mathrm{t}$ rap concentration decreases.

\section{Conclusions}

Three HFIR neutron-irradiated tungsten samples were exposed to deuterium plasma (ion fluence of $\left.1 \times 10^{26} \mathrm{~m}^{-2}\right)$ at three different temperatures $\left(100,200\right.$, and $\left.500{ }^{\circ} \mathrm{C}\right)$ in TPE, and TDS was performed with a $\mathrm{r}$ amp-rate of $10{ }^{\circ} \mathrm{C} \min ^{-1}$ up to $900^{\circ} \mathrm{C}$ and a $\mathrm{n}$ a nnealing at $900^{\circ} \mathrm{C}$ for 0.5 ho ur. $\mathrm{T}$ hese procedures wer e r epeated to u ncover d efect-annealing ef fects on d euterium $r$ etention. $\mathrm{T}$ he $\mathrm{r}$ esults show that deuterium retention decreases approximately $70 \%$ for at $500{ }^{\circ} \mathrm{C}$ after each annealing, and all $\mathrm{t}$ he $\mathrm{r}$ adiation damage was $\mathrm{n}$ ot annealed out co mpletely ev en af ter $\mathrm{t}$ he $3^{\text {rd }}$ annealing. T MAP 

modeling $\mathrm{r}$ evealed $\mathrm{t}$ he $\mathrm{t}$ rap co ncentration $\mathrm{d}$ ecreases ap proximately $80 \%$ af ter each an nealing at $201900{ }^{\circ} \mathrm{C}$ for 0.5 hour.

202

\section{Acknowledgements}

204

This work was prepared for the U.S. Department of Energy, Of fice of F usion Energy Sciences, under the DOE Idaho Field Office contract number DE-AC07-05ID14517. 


\section{References}

[1] N. Taylor, D. Baker, S. Ciattaglia, P. Cortes, J. Elbez-Uzan, M. Iseli, S. Reyes, L. RodriguezRodrigo, S. Rosanvallon, L Topilski, Fus. Eng. Des. 86 (2011) 619

[2] N. Taylor, S. Ciattaglia, P. Cortes, M. Iseli, S. Rosanvallon, and L. Topilski, Fus. Eng. Des. 87 (2012) 476

[3] N. Taylor, C. Alejaldre, and P. Cortes, Fus. Sci. Technol. 64 (2013) 111

[4] Y. Hatano, M. Shimada, V.Kh. Alimov, J. Shi, M. Hara, T. Nozaki, Y. Oya, M. Kobayashi, K. Okuno, T. Oda, G. Cao, N. Yoshida, N. Futagami, K. Sugiyama, J. Roth, B. Tyburska-Püschel, J. Dorner, I. Takagi, M. Hatakeyama, H. Kurishita, and M.A. Sokolov, J. Nucl. Mater. 438 (2013) S114-S119

[5] Y. Hatano, M. Shimada, T. Otsuka, Y. Oya, V.Kh. Alimov, M. Hara, J. Shi, M. Kobayashi, T. Oda, G. Cao, K. Okuno, T. Tanaka, K. Sugiyama, J. Roth, B. Tyburska-Püschel, J. Dorner, N. Yoshida, N. Futagami, H. Watanabe, M. Hatakeyama, H. Kurishita, M.A. Sokolov, and Y. Katoh, Nucl. Fusion 53 (2013) 073006

[6] H. Schultz, "The Landolt-Börnstein Database (http://www.springermaterials.com)" volume III/25 "Atomic Defects in Metals" (Springer Materials 1991), ed Ullmaier H, section 2.2.3. DOI: $10.1007 / 10011948$ 54

[7] M. Shimada, R. D. Kolasinski, J. P. Sharpe, and R. A. Causey, Rev. Sci. Instrum. 82 (2011) 083503.

[8] B. Lipschultz, J. Roth, J.W. Davis, R.P. Doerner, A.A. Haasz, A. Kalenbach, A. Kirschner, R.D. Kolasinski, A. Loarte, V. Philipps, K. Schmid, W.R. Wampler, G.M. Wright, and D.G. Whyte, "An assessment of the current data affecting tritium retention and its use to project towards $T$ retention in ITER", MIT Report PSFC/RR-10-4, 2010

[9] M. Shimada, G. Cao, Y. Hatano, T. Oda, Y. Oya, M. Hara, and P. Calderoni, Phys. Scr. T145 (2011) 014051

[10] C.N. Taylor, M. Shimada, B.J. Merrill, D.W. Akers, Y. Hatano, submitted to J. Nucl. Mater. this special issue

[11] G.R. Longhurst, D.F. Holland, J.L. Jones, and B.J. Merrill, “TMAP4 User’s Manual”, Idaho National Laboratory, EGG-FSP-10315 (1992)

[12] G.R. Longhurst, “TMAP7: Tritium Migration Analysis Program,” User Manual, Idaho National Laboratory, INEEL/EXT-04-02352, Rev. 2 (2008)

[13] B.J. Merrill, M. Shimada, and P.W. Humrickhouse, J. Plasm. Fus. Res. SERIES, 10 (2013) 71

[14] R.A. Causey, K. Wilson, T. Venhaus, and W.R. Wampler, J. Nucl. Mater. 266-269 (1999) 467471

[15] T. Venhaus, R.A. Causey, R.P. Doerner, and T. Abeln, J. Nucl. Mater. 290-293 (2001) 505-508

[16] T. Venhaus, and R.A. Causey, Fusion Technology, 39 (2001), 868-873

[17] M. Shimada, G. Cao, T. Otsuka, M. Hara, M. Kobayashi, Y. Oya, and Y. Hatano, submitted to Nuclear Fusion.

[18] Stopping and Range of Ions in Matter (SRIM), J.F. Ziegler, http://www.srim.org

[19] R. Frauenfelder, J. Vac. Sci. Technol. 6 (1969) 388

[20] R.A. Anderl, D.F. Holland, G.R. Longhurst, R.J. Pawelko, C.L. Trybus, and C.H. Sellers, Fusion Technol. 21 (1992) 745

[21] R.A. Ariani, Acta Metall. 18 (1970) 147

Page 9 
Tables

Table 1. The experimental (HFIR irradiation ${ }^{\mathrm{a}}$ and TPE plasma ${ }^{\mathrm{b}}$ ) conditions.

\begin{tabular}{|c|c|c|c|c|c|c|c|c|}
\hline \multirow[b]{2}{*}{$\begin{array}{l}\text { Sample } \\
\text { ID }\end{array}$} & \multirow[b]{2}{*}{$\begin{array}{l}\text { Weight } \\
\text { [gram] }\end{array}$} & \multirow{2}{*}{$\begin{array}{c}\text { Sample size }^{\mathrm{c}} \\
\text { (diameter / } \\
\text { thickness) } \\
{[\mathrm{mm}]} \\
\end{array}$} & \multirow{2}{*}{$\begin{array}{l}\text { HFIR } \\
\text { irradiation } \\
\text { dose } \\
\text { [dpa] } \\
\end{array}$} & \multirow{2}{*}{$\begin{array}{c}\mathrm{TPE} \\
\text { exposure } \\
\text { temperature } \\
{\left[{ }^{\circ} \mathrm{C}\right]} \\
\end{array}$} & \multicolumn{4}{|c|}{ Ion fluence $^{\mathrm{d}}\left[\mathrm{m}^{-2}\right]$} \\
\hline & & & & & no-anneal $^{\mathrm{g}}$ & $\begin{array}{l}\text { after } 1^{\text {st }} \\
\text { anneal }^{\mathrm{g}}\end{array}$ & $\begin{array}{c}\text { after } 2^{\text {nd }} \\
\text { anneal }^{\mathrm{g}}\end{array}$ & $\begin{array}{l}\text { after } 3^{\text {rd }} \\
\text { anneal }^{\mathrm{g}}\end{array}$ \\
\hline Y102 & 0.80 & $6.0 / 0.15$ & 0.025 & 100 & $1.0 \mathrm{E}+26$ & $1.0 \mathrm{E}+26$ & $6.3 \mathrm{E}+25^{\mathrm{f}}$ & $4.2 \mathrm{E}+25^{\mathrm{f}}$ \\
\hline Y103 & 0.89 & $6.0 / 0.16$ & 0.025 & 200 & $9.7 \mathrm{E}+25$ & $1.0 \mathrm{E}+26$ & $1.0 \mathrm{E}+26$ & $9.8 \mathrm{E}+25$ \\
\hline Y105 & 0.83 & $6.0 / 0.15$ & 0.025 & 500 & $1.2 \mathrm{E}+26$ & $1.0 \mathrm{E}+26$ & $6.1 \mathrm{E}+25^{\mathrm{f}}$ & $9.8 \mathrm{E}+25$ \\
\hline
\end{tabular}

${ }^{\mathrm{a}} \mathrm{HFIR}$ irradiation temperature was at the reactor coolant temperature of $50-70{ }^{\circ} \mathrm{C}$

${ }^{\mathrm{b}}$ Incident ion energy was approximately $100 \mathrm{eV}$ for all samples.

${ }^{\mathrm{c}, \mathrm{d}}$ Sample thickness varies due to slicing $6 \mathrm{~mm}$ diameter tungsten rod. This variation in the sample thickness made it challenging to obtain identical flux and temperature conditions for different thickness sample. The ion fluences in each TPE plasma exposure were kept approximately $1 \times 10^{26} \mathrm{~m}^{-2}$, for each sample.

${ }^{\mathrm{f}}$ Desired ion fluences $\left(1 \times 10^{26} \mathrm{~m}^{-2}\right)$ were not achieved due to poor plasma performances and plasma fluctuations.

${ }^{\mathrm{g}}$ We denote the samples that performed no TDS and no annealing after neutron-irradiation as "noanneal", the samples performed one TDS and one annealing as "after $1^{\text {st }}$ anneal", the samples performed two TDS and two annealing as "after $2^{\text {nd }}$ anneal", and the samples performed three TDS and three annealing as "after $3^{\text {rd }}$ anneal". 


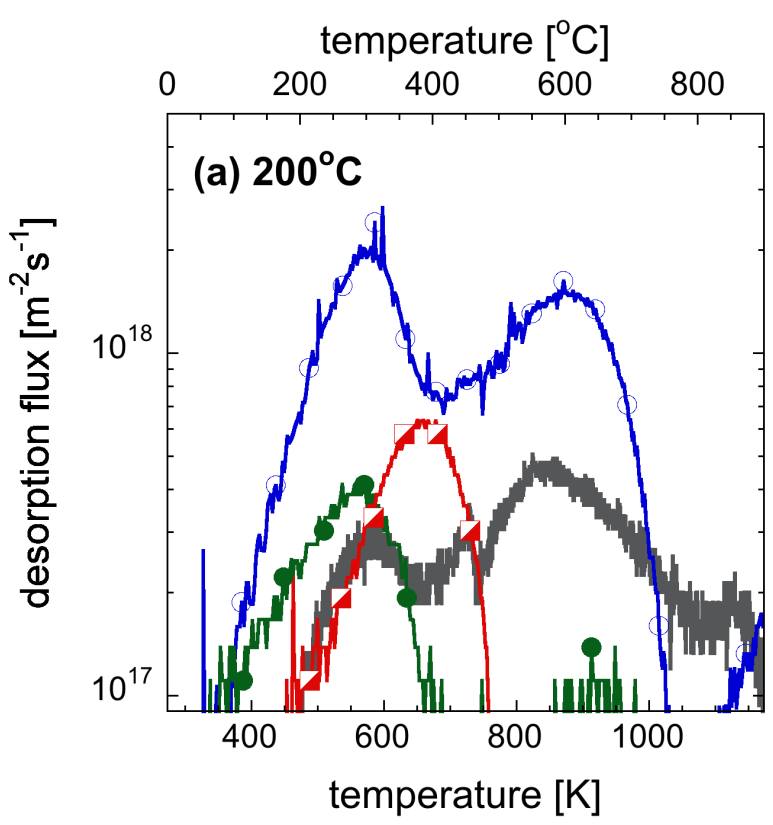

Fig. 1: Thermal desorption spectra of annealed neutron-irradiated tungsten samples exposed to the total ion fluence of $1 \times 10^{26} \mathrm{~m}^{-2}$ at (a) $200{ }^{\circ} \mathrm{C}$ and (b) $500{ }^{\circ} \mathrm{C}$. Solid line denotes for no anneal, line with open circle denotes for after $1^{\text {st }}$ anneal, line with solid circle denotes for after $2^{\text {nd }}$ anneal, and line with square denotes after $3^{\text {rd }}$ anneal. 

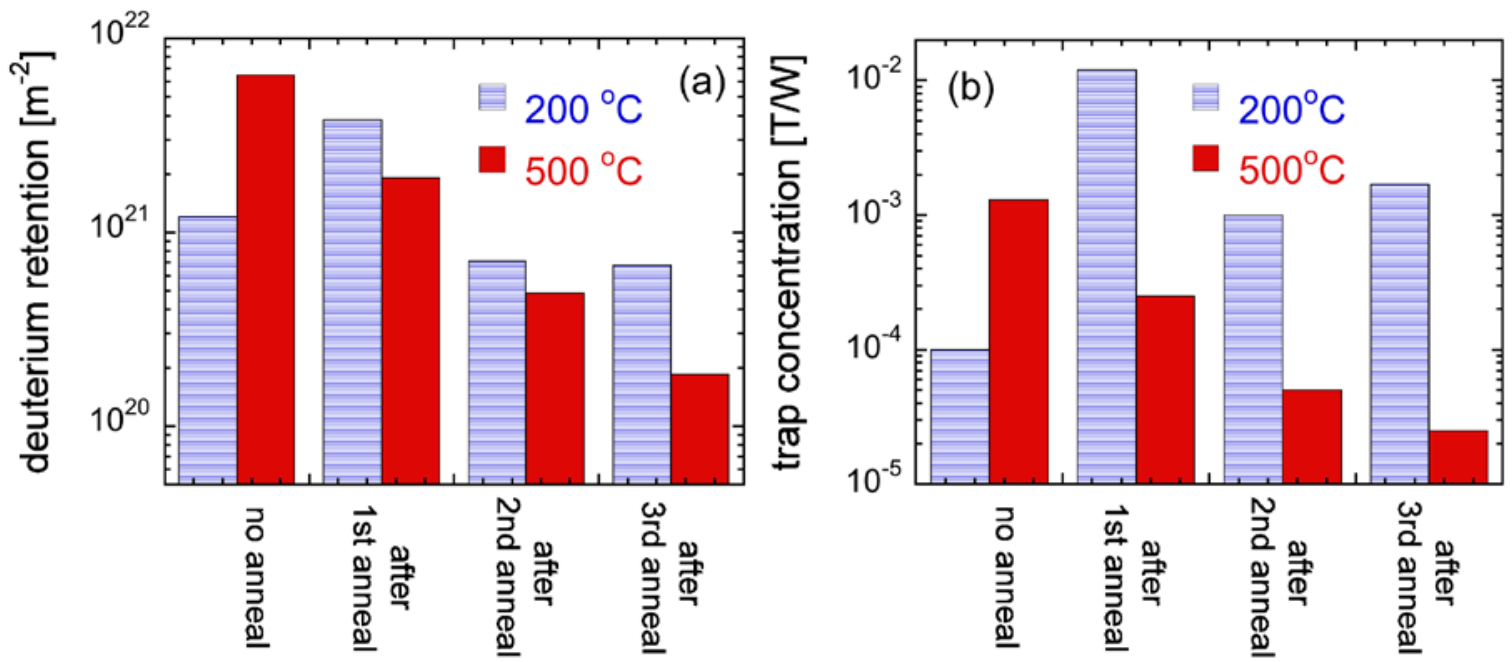

Fig. 2: Defect annealing effects on (a) deuterium retention obtained experimentally via TDS and (b) trap concentration obtained numerically via TMAP at two different plasma exposure temperatures $281\left(200\right.$, and $\left.500{ }^{\circ} \mathrm{C}\right)$.

[figure width: two column $(160 \mathrm{~mm})$, height: $71 \mathrm{~mm}$, color, filename: “Shimada PSI2014 Fig2.tif'] 